\title{
A new species of Sinophasma Günther, 1940 from Guangxi, China (Phasmida: Diapheromeridae: Necrosciinae)
}

\author{
Ho Wai-chun George ${ }^{1}$ \\ 1 Hong Kong Entomological Society, P. O. Box No.73749, Kowloon Central Post Office, Hong Kong \\ † http://zoobank.org/3173965C-4FAA-4DE4-9E2D-3CDD92945216 \\ http://zoobank.org/A402A988-4127-474C-BFBE-A3BA80E4DDA1 \\ Corresponding author: Ho Wai-chun George (georgehwc@hotmail.com)
}

\begin{abstract}
Received 25 January 2014

Accepted 08 March 2014
\end{abstract}

Published 30 May 2014

Academic editor:

Susanne Randolf

\section{Key Words}

Stick Insects

Necrosciini

Taxonomy

Damingshan

Mainland China

Oriental Region

\section{Introduction}

The genus Sinophasma Günther, 1940 is mainly distributed over China and Taiwan (Shiraki 1935; Otte and Brock 2005; Hennemann et al. 2008; Chen and He 2008; Ho 2012; Huang 2013). S. vietnamense Chen \& Chen, 1999 from North Vietnam is the only species known from outside China and Taiwan. Currently twenty-six species and two subspecies are recognized in this Palaearctic and Oriental genus. The major revisionary work was provided by Chen and He (2008) and a revised key was provided by Ho (2012). The author recently conducted a collecting trip to Damingshan, located at the south-central Guangxi, China, and discovered a new species, S. damingshanensis sp. n., described and illustrated in this study.

\section{Material and methods}

The specimen was collected directly by hand at night due to their nocturnal behavior. A hand torch was used to spot them on the plants. The type specimens of Sinophasma damingshanensis sp. n. are deposited in Hong Kong Entomological Society (HKES). Morphological terms largely follow Bragg (2001) and Zompro (2004).

\section{Results}

\section{Sinophasma Günther, 1940}

http://species-id.net/wiki/Sinophasma

Sinophasma Günther, 1940: 240.

Type species: Sinophasma klapperichi Günther, 1940, by original designation. 


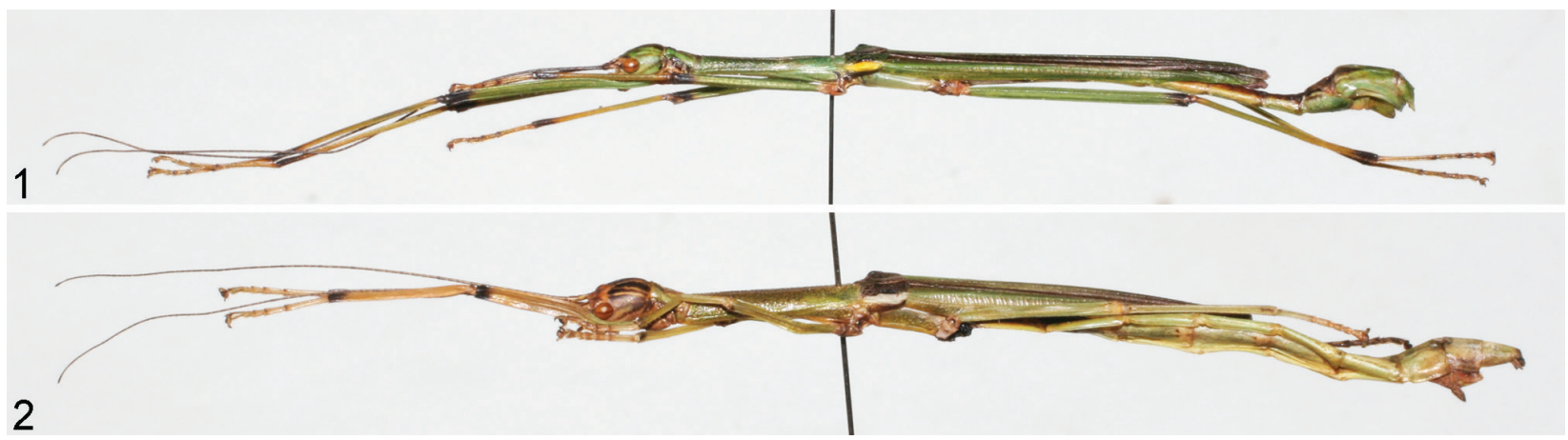

Figures 1-2. Habitus images of Sinophasma damingshanensis sp. n. 1. Male, lateral view; 2. Female, lateral view.

Notes: While only one species occurs in Vietnam, all other twenty-five species and two subspecies are endemic to China.

\section{Sinophasma damingshanensis Ho, sp. n.}

http://zoobank.org/1083CC13-A904-4D1F-81F2-BC6AE050F016

http://species-id.net/wiki/Sinophasma_damingshanensis

Figures 1-6

Description: Male. Medium-sized. General colour of body, wings and legs green. Body slender and slim.

Head green, with six blackish longitudinal stripes reaching hind margin of head. Smooth, lacking granulation. Oval, longer and broader than pronotum, slightly constricted behind eyes posteriorly. Vertex flat, with an oval and shallow depression between bases of antennae. Occiput convex, with distinct median furrow, lateral furrows indistinct. Compound eyes light brown, rounded and prominent, about 1.5 times length of genae. Antennae dark brown, densely covered with setae; filiform, longer than forelegs; first segment flattened at base, rectangular, parallel-sided, about 1.5 times length of second segment, shorter than third segment; second and third segments cylindrical.

Pronotum rectangular, transverse and longitudinal sulci crossing before middle, anterior margin curved inward, hind margin slightly rounded. Mesonotum densely granulated, elongate, more than 4 times length of pronotum, slightly parallel-sided, median line distinct, with a long carina along lateral margins. Mesopleura and mesosternum with inconspicuous and dense granules. Metapleura and metasternum smooth.

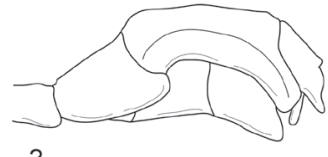

3

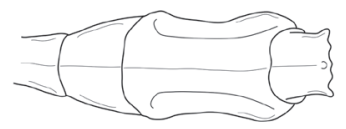

4
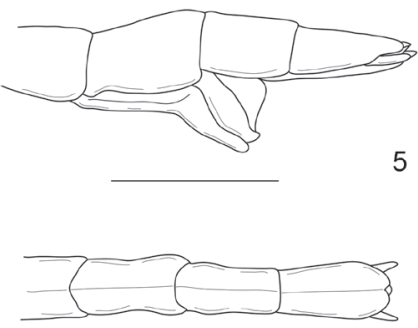

6
Figures 3-6. Sinophasma damingshanensis sp. n. from Guangxi, China. 3. Male, terminal end of abdomen, lateral view; 4. Male, terminal end of abdomen, dorsal view; 5. Female, terminal end of abdomen, lateral view; 6 . Female, terminal end of abdomen, dorsal view. [scale bar $=5 \mathrm{~mm}$ ].
Abdomen dorsally green with brownish markings, ventral surface yellowish green. Smooth. Cylindrical and slender. Second to six terga parallel-sided, roughly equal in length. Seventh tergum gently expanded posteriorly. Eighth tergum trapezoid, gradually expanded posteriorly. Ninth tergum elongate and swollen, the longest, distinctly constricted medially, hind margin deeply emarginated; posterolateral angles elongate distinctly, apices obtuse; lateral margins raised. Anal segment rectangular, with a small horn medially; with ninth tergum vertically, longer than eighth tergum, reaching hind margin of anal segment; hind margin with four small emarginations, lateral angles elongate tuberculately. Poculum cup-shaped, hind margin rounded and broad. Cerci long and straight, cylindrical, apices rounded, not surpassing end of anal segment.

Tegmina brownish black, elevated angle blunt, with a yellow longitudinal stripe being laterad of elevation; oval, slightly as long as head, subtruncate posteriorly. Alae green, with dark brown longitudinal band, anal region dull rose; long, reaching posterior region of sixth tergum.

Legs slender and long. Unarmed, covered with dense and short bristles. Coxae rufous brown. Femora and tibiae green, black apically. Tarsi orange brown.

Female. Similar to male, but distinctly larger and robust. General colour of body, wings and legs green. Body slender and cylindrical.

Head greenish brown to light brown, occiput with six black longitudinal bands segregated by light brown longitudinal stripes. Smooth. Oval, distinctly longer than wide. Vertex flat, with a small oval depression between bases of antennae, its diameter as long as second antennal segment. Occiput distinctly convex, with median and lateral furrows. Compound eyes light brown, oval, about 2.5 times length of genae. Antennae dark brown, filiform, longer than forelegs; first segment slightly flattened at base, about 1.8 times length of second segment, as long as third segment.

Pronotum green, shorter than head, gently expanded posteriorly, with transverse and longitudinal sulci crossing before middle, anterior margin curved inward, hind margin truncate. Mesonotum green, densely covered with yellow and small granules; about 4 times length of pronotum, median line indistinct. Mesopleura, mesosternum, metapleura and metasternum densely granulated as in mesonotum. Metanotum smooth, longer than median segment. 
Abdomen dorsally and ventrally yellowish green. Smooth. Cylindrical, tapering posteriorly. Second to six terga roughly equal in length. Eighth tergum dilated into a slight and rounded lobe posterolaterally. Seventh sternum lacking preopercular organ. Anal segment slightly longer than ninth tergum, with small U-shaped notch on hind margin, lateral angles rounded. Supra-anal plate very small, hind margin rounded, exceeding hind margin of anal segment. Subgenital plate scoop-shaped, distinctly decurved in second half, strongly carinate laterally, apex pointed. Gonapophyses exposed, apex obtuse, reaching middle of ninth tergum. Cerci light brown, straight and cylindrical, apices pointed, surpassing hind margin of anal segment.

Tegmina brownish black, with light brown veins, elevated angle blunt, with a pale white longitudinal stripe being laterad of elevation; oval, longer than head, hind margin truncate. Alae green with dark brown longitudinal band, anal region dull rose; long, reaching middle of fifth tergum.

Legs slender and long. Unarmed. Coxae buff brown. Profemora and protibiae rufous green. Mesofemora, mesotibiae, metafemora and metatibiae green. Apices of femora and tibiae black. Tarsi rufous brown.

Measurements. Length (mm): Holotype: $\lambda$, body length 52.0, antennae 41.0, head 3.0, pronotum 2.0, mesonotum 9.5, metanotum including median segment 7.5, profemora 14.0, mesofemora 10.0, metafemora 15.0, protibiae 12.0, mesotibiae 9.0, metatibiae 14.0. Paratypes: $\hat{\jmath}$, body length 51.0-52.0, antennae 34.0-36.0, head 3.0-3.5, pronotum 2.0-2.2, mesonotum 9.5, metanotum including median segment 7.0, profemora 12.5-13.0, mesofemora 9.0-10.0, metafemora 14.0, protibiae 11.0-12.0, mesotibiae 9.0, metatibiae 13.0-14.0, tegmina 2.5-3.0, alae 22.025.0. Paratypes: 9 , body length 59.0-73.0, antennae 29.0-43.0, head 4.0-5.0, pronotum 2.5-3.0, mesonotum 11.5-14.0, metanotum including median segment 7.0, profemora 11.0-15.0, mesofemora 8.0-10.0, metafemora 12.0-15.0, protibiae 9.0-14.0, mesotibiae 7.0-9.0, metatibiae 10.0-14.0, tegmina 3.5-4.5, alae 25.0-28.0.

Type material: China: holotype: $\hat{\sigma}$, Damingshan, Wuming, Guangxi, 28-31.VII.2012, Ho Wai-Chun

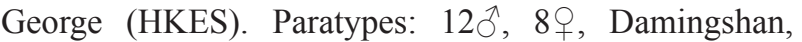
Wuming, Guangxi, China, 28-31.VII.2012, Ho WaiChun George (HKES).

Etymology: This species is named after the type-locality, Damingshan.

Distribution: Guangxi, China.

Notes: This species is found in evergreen broadleaf forests.

Differentiation: Small Sinophasma species. This new species is separated from most species in the genus by its rectangular anal segment with a small horn medially in male and seventh sternum lacking preopercular organ in female. S. damingshanensis Ho, sp. n. [Guangxi, China] is related to S. unispinosum Chen \& Chen, 1997 [Guangdong, China] but can be separated by its greenish colour, smaller size and slenderer body in both sexes; absence of preopercular organ and decurved subgenital plate in female; and posterolaterally tuberculate anal segment in male.

\section{Acknowledgements}

The author is grateful to the staff of Damingshan Nature Reserve, Guangxi for their kind assistance and the anonymous reviewers for providing valuable comments to improve the manuscript.

\section{References}

Bragg PE (2001) Phasmids of Borneo. Natural History Publications, Kota Kinabalu, Borneo.

Chen SC, Chen PC (1997) Descriptions of two new species and one unknown female of the genus Sinophasma from Guangdong Province, China (Phasmatodea: Heteronemiidae). Journal of Beijing Forestry University 6(2): 93-99.

Chen SC, Chen PC (1999) A new species of Sinophasma from Viet Nam (Phasmatodea: Heteronemiidae). Acta Entomologica Sinica 42(3): 300-302.

Chen SC, He YH (2008) Phasmatodea of China. China Forestry Publishing House, Beijing.

Günther K (1940) Neue Stabheuschrecken (Phasmoïden) aus China. Decheniana 237: 237-248

Hennemann FH, Conle OV, Zhang WW (2008) Catalogue of the stick and leaf-insects (Phasmatodea) of China, with a faunistic analysis, review of recent ecological and biological studies and bibliography (Insecta: Orthoptera: Phasmatodea). Zootaxa 1735: 1-76.

Ho GWC (2012) Notes on the genera Sinophasma Günther, 1940 and Pachyscia Redtenbacher, 1908 (Phasmatodea: Diapheromeridae: Necrosciinae), with the description of four new species from China. Zootaxa 3495: 57-72.

Huang YSF (2013) Sinophasma hoenei formosanum Y.S. Huang, subsp. n., a new subspecies of stick insect from Taiwan (Phasmida: Diapheromeridae: Necrosciinae). Phasmid Studies 18: 39-51.

Otte D, Brock PD (2005) Phasmida Species File - Catalog of stick and leaf insects of the world. The Insect Diversity Association and the Academy of Natural Sciences, Philadelphia.

Shiraki T (1935) Orthoptera of the Japanese Empire (Part IV) Phasmidae. Memoirs of the Faculty of Science and Agriculture, Taihoku lmperial University, Formosa 14: 23-88.

Zompro O (2004) Revision of the genera of the Areolatae, including the status of Timema and Agathemera (Insecta, Phasmatodea). Abhandlungen des Naturwissenschaftlichen Vereins Hamburg (NF) 37: 1-327. 
